Como citar este artigo:

DA SILVA, TÂNIA MARIA C.;

BERNUCI, MARCELO P.; MARQUES,

ANDRÉA G.; GARCIA, LUCAS F.;

TOLOTTI, NEUSA C. R.; DA SILVA,

ANDRÉA T. C.; Violência praticada

por parceiros íntimos e saúde:

representações de mulheres de

um município do Paraná. Revista

Saúde (Sta. Maria). 2020; 46 (1).

\author{
Autor correspondente: \\ Nome: Tânia Maria Comes Da \\ Silva \\ E-mail: tania.gomes@unicesumar. \\ edu.br \\ Telefone: (44) 99933-0739 \\ Formação Profissional: Mestrado, \\ doutorado e pós-doutorado \\ em História pela Universidade \\ Federal do Paraná. Professora \\ Permanente do Programa de \\ Pós-graduação em Promoção da \\ Saúde e do curso de Medicina \\ do Centro Universitário de \\ Maringá - UniCesumar. Bolsista \\ produtividade em Pesquisa do \\ Instituto Cesumar de Ciência, \\ Tecnologia e Inovação - ICETI.
}

Filiação Institucional: UniCesumar Endereço para correspondencia:

Rua: Av. Guedner, n०1610

Bairro: Jardim Aclimacao

Cidade: Maringá

Estado: Paraná

CEP: 87050-900

Data de Submissão:

24/0 I/2020

Data de aceite:

$01 / 04 / 2020$

Conflito de Interesse: Não há

conflito de interesse

\section{Violência praticada por parceiros íntimos e saúde: representações de mulheres de um município do Paraná}

\author{
Violence by intimate partner and health: representations \\ of women from a city in Paraná, Brazil
}
Tânia Maria Gomes da Silva, Marcelo Picinin Bernuci, Andréa Grano Marques, Lucas França Garcia, Neusa Gomes Rodrigues Tolotti, Andréa Tenório Correia da Silva

\section{RESUMO}

Tratou-se de estudo qualitativo, exploratório, utilizando a metodologia da história oral, através de entrevistas semiestruturadas realizadas com quatro moradoras de um município paranaense, vítimas de violência praticada por parceiros íntimos. Objetivou-se analisar representações da violência numa perspectiva geracional e perceber relações entre violência e adoecimento. 0 exame das narrativas utilizou o método da análise de conteúdo, com suporte na Teoria das Representações Sociais. A pesquisa empírica evidenciou que abusos físicos e psicológicos são identificados como violência, tensionando a vida e comprometendo a saúde; que a violência resulta de permanências culturais que legitimam dissimetrias nas relações conjugais, prevalecendo a subalternidade feminina; a pobreza dificulta o rompimento das relações e a rede de apoio é frágil. Concluiu-se pela necessidade de uma organização social que promova a igualdade de gênero para 0 enfrentamento da violência, disseminação da cultura da paz e promoção da saúde.

PALAVRAS-CHAVE: Violência de Gênero; História oral; Representação Social; Promoção da Saúde.

\section{ABSTRACT}

It is a qualitative, exploratory study, using oral history methodology, through semi-structured interviews with four residents of a municipality of Paraná, victims of violence practiced by intimate partners. The objective is to analyze representations of violence from a generational perspective and to understand the relationship between violence and illness. The examination of the narratives uses the method of content analysis, supported by the Theory of Social Representations. Physical and psychological abuse are identified as violence; poverty hampers the disruption of abusive relationships; the violence practiced by intimate partners is identified as a stressing element of life and compromising health. Empirical research confirms that violence results from cultural permanences that legitimize asymmetries in conjugal relations, prevailing female subalternity. It is concluded that there is a need for a social organization that promotes gender equality in order to confront violence, disseminate a culture of peace and promote health.

KEYWORDS: Gender Violence; Oral History; Social Representations; Health Promotion. 


\section{INTRODUÇÃO}

A violência contra as mulheres é um problema mundial de saúde pública. Classifica-se em física, psicológica, patrimonial e sexual; incluindo abusos físicos e psicológicos, estupros, assédios, mutilação genital, crimes de honra e tráfico de mulheres, resultado da desigualdade que marca as relações masculino/feminino¹.

No Brasil, discussões da violência praticada por parceiros íntimos iniciaram na década de 1970 na esteira das reivindicações do movimento feminista, ganhando visibilidade nos anos 80. Nos anos 90 o tema penetrou na área da saúde. Foram os pediatras, os psiquiatras e os profissionais da assistência social os primeiros a estabelecerem esse link, a partir do entendimento de que os maus tratos que atingiam as crianças incidiam igualmente sobre suas mães².

A violência contra as mulheres é também denominada violência de gênero. Portador de uma nova epistemologia, gênero é um conceito transdisciplinar, difundido nas ciências a partir dos anos 1980, que busca explicar as diferenças entre ser homem e ser mulher a partir de traços históricos, culturais e políticos, ao invés de unicamente por meios biologizantes e inscritos nos corpos sexuados. Na perspectiva de gênero, masculino e feminino não são categorias estáticas, resultado de corpos preexistentes sobre os quais se constroem conhecimentos neutros, mas o resultado de um processo de aprendizagem sociocultural que modela comportamentos. Comportamentos esses que, apresentados como verdades científicas, legitimam desigualdades: masculino/superior; feminino/inferior ${ }^{3}$. Associado à raça/etnia, classe, sexualidade e outros marcadores identitários, gênero influencia decisivamente a vida das pessoas.

Violência de gênero ocorre em países de baixa, média e alta renda. Nos Estados Unidos, 35,6\% das mulheres sofreram violências praticadas pelos parceiros em algum momento de suas vidas ${ }^{4}$. No Brasil, em 2017, mais de 221 mil mulheres procuraram delegacias de polícia para registros de violência doméstica. Os feminicídios no país cresceram 20,7\% em dez anos, passando de 3,9, em 2010, para 4,7 mulheres assassinadas por grupo de 100 mil, em 2017; 28,5\% na residência das vítimas, tornando o domicílio local de alto potencial de insegurança para as mulheres ${ }^{5}$.

Este artigo discute a violência praticada por parceiro íntimo, tendo como suporte documental as narrativas de quatro moradoras da periferia de um município paranaense de médio porte. Suas idades são 52, 65, 74 e 82 anos. Todas têm baixo capital cultural e econômico. Objetivou-se conhecer as representações da violência e identificar a percepção das vítimas quanto à relação entre violência e saúde numa perspectiva geracional. $\mathrm{O}$ estudo, de caráter históricoqualitativo, buscou "novos horizontes analíticos para as condições de emergências de saberes voltados à explicação do social na determinação de processos patológicos e das práticas de saúde [...]”'.

\section{MÉTODO}

Estudo qualitativo, de abordagem exploratória, que usou como método de produção de dados entrevistas semiestruturadas, na perspectiva metodológica da história oral, permitindo ao pesquisador o acesso à historicidade das 
vidas privadas ${ }^{7}$.

Foram convidadas a participar do estudo mulheres com história prévia de violência praticada por parceiro íntimo, usuárias de uma instituição de caráter assistencial a famílias de baixa renda em um município do noroeste do Paraná. Todas eram moradoras de bairros da periferia do município e apresentavam baixo capital cultural e econômico.

Buscando privilegiar a perspectiva geracional, estiveram envolvidas mulheres com 52, 65, 74 e 82 anos de idade. A amostra se deu por conveniência e não por critério estatístico e as narrativas expressaram as representações sociais apreendidas por cada uma das integrantes do estudo. A coleta de dados ocorreu de agosto a dezembro de 2017.

Inicialmente, foi realizado um encontro inicial para explicar detalhadamente às mulheres os propósitos da pesquisa, anotar os dados sociodemográficos e conhecer de maneira mais generalizada a história de vida delas. Tratouse de um encontro bastante informal, uma "visita" no entendimento de uma delas. Em média, essas conversas duraram uma hora e meia. Na sequência, dois outros encontros foram realizados para a realização das entrevistas. Estas foram individuais, gravadas e transcritas na íntegra, tendo sido realizadas na casa das entrevistadas. Houve uma exceção, e tratou-se de uma mulher que preferiu um lugar neutro para dar o seu depoimento, uma vez que vivia com um novo companheiro, diferentemente das demais que não tinham parceiros íntimos. Evitaram-se perguntas que pudessem levar a duplo sentido ou que possibilitassem uma gama ampliada de respostas.

Para a análise, foi criado um quadro contendo o nome de cada entrevistada, no qual os principais tópicos das entrevistas foram listados. Isso permitiu que se visualizasse de maneira mais precisa a recorrência das informações, identificando a repetição das ideias e permitindo que, sem elementos novos, se alcançasse o ponto de saturação teórica. $\mathrm{O}$ caderno de campo também ajudou a elaborar os registros cotidianos, potencializando as possibilidades de compreensão da população estudada.

A interpretação dos dados se realizou na perspectiva da análise de conteúdo de $\operatorname{Bardin}^{8}$, seguindo as fases pré-estabelecidas pela autora: a pré-análise; a exploração do material; o tratamento dos resultados; a inferência e a interpretação. A pré-análise é a fase da escolha e organização da documentação a ser trabalhada, correspondendo a um período basicamente intuitivo, mas objetivando sistematizar as ideias que fundamentarão a interpretação final dos dados. Nela, buscou-se conhecer o material por meio da leitura flutuante, seguida da escolha documental, sendo cumpridas as regras de exaustividade, homogeneidade e representatividade, isso é, evitando que algum documento ficasse de fora da análise e garantindo que todos guardassem correlação com os objetivos propostos pela pesquisa. Concluída adequadamente a pré-análise, teve início a exploração do material, sendo identificadas as categorias de análise; que, por sua vez, foram repartidas em subcategorias. Por fim, os resultados brutos foram tratados de maneira a serem significativos.

A proposta de interpretação se valeu da Teoria das Representações Sociais, enfatizando a interação entre sujeito 
e sociedade para a construção da realidade. Moscovici define as representações como teorias do senso comum que os diferentes sujeitos constroem acerca de um objeto, dando-lhe sentidos e orientando formas de comportamento em relação a ele ${ }^{9}$. São registros simbólicos e têm relação com a maneira como os indivíduos conhecem o real: o que é um ato de violência? O que motiva a violência? Como enfrentar a violência? Não se resumem a meras opiniões individuais, mas são o resultado de conhecimentos que circulam socialmente e são "apanhados" pelos indivíduos. Tampouco devese pensar as representações sociais como estruturas cristalizadas e estáticas, pois há nelas uma dinamicidade com a qual se abrem continuamente às novas formas de pensar sobre os fatos pouco familiares, dando ensejo à construção de novas representações.

Moscovici fala em dois processos inerentes às representações sociais: ancoragem e objetivação. Ancorar é classificar e nomear algo desconhecido, transformando-o em familiar; dando ensejo a uma nova representação. A objetivação é o mecanismo, segundo o qual a representação se torna realidade concreta, física, cópia da realidade. Ambos são mecanismos geradores de representações sociais que permitem aos indivíduos construírem um entendimento sobre o mundo ${ }^{9}$. Optou-se pelas entrevistas como forma de apreender as representações da violência que emergem das histórias orais coletadas, considerando-as tanto o resultado de pensamentos construídos individualmente quanto interrelações entre as entrevistadas e o seu grupo social. Representações sociais são registros simbólicos e têm relação com a maneira como os indivíduos conhecem o real, estando sempre abertas às novas formas de pensar o mundo

$\mathrm{O}$ artigo analisa as narrativas femininas, com foco na percepção das representações da violência e suas consequências no contexto da saúde. Insere-se dentro de uma perspectiva historiográfica que busca dar visibilidade aos sujeitos normalmente silenciados pela história: mulheres pobres, não escolarizadas e moradoras de pequenos municípios.

\section{CONSIDERAÇÕES ÉTICAS}

O estudo seguiu a Resolução n 466/2012 e foi aprovado pelo Comitê de Ética do Centro Universitário de Maringá (UniCesumar) sob o parecer $n^{0} 234.231 / 2017$. Foi garantido o sigilo e privacidade às participantes, assim como o direto de retirar o consentimento a qualquer momento do estudo. 0 termo de consentimento livre e esclarecido (TCLE) foi apresentado às mulheres. Todas as participantes preencheram o TCLE.

\section{RESULTADOS E DISCUSSÃO}

As entrevistadas têm baixo capital econômico e cultural. Buscou-se prioritariamente conhecer o universo de 
significados e representações dessas mulheres, conhecendo-as em suas subjetividades. Todas receberam um nome fictício.

Roselaine, 56, parda, analfabeta, viveu várias uniões consensuais desde os 12 anos. Separada. Duas filhas que não chegou a criar. Ex-coletora de materiais recicláveis, desempregada. Mora com a irmã. Vítima de violência física e psicológica.

Nair, 65, parda, ensino fundamental I, casou-se aos 18 anos. Viúva, vive atualmente em união consensual. Quatro filhas. Pensionista de um salário mínimo. Vítima de violência psicológica no primeiro relacionamento.

Rosa, 74, parda, analfabeta, casou-se aos 17 anos. Viúva. Cinco filhos. Pensionista de um salário mínimo. Vítima de violência física, psicológica e patrimonial.

Joana, 82, branca, analfabeta, casou-se aos 19 anos. Viúva. Cinco filhos. Pensionista de um salário mínimo. Mora com a neta. Vítima de violência psicológica.

\section{ANÁLISE INTERPRETATIVA}

\section{(i) Tipologias de violência}

Subcategorias: física, psicológica, patrimonial

A violência fez parte da vida das participantes. A violência física envolve agressões ao corpo e a psicológica se materializa por meio de humilhações, ameaças, constrangimentos, chantagens, tendendo a evoluir e eclodir na forma de violência física. A patrimonial envolve destruição ou retenção dos bens materiais da vítima²,10.

Rosa: "Ele chegava na roça me batendo. Falava que eu era burra, que ele arrumava uma mulher muito melhor do que eu. Aí depois pegou de ruindade e começou a ir desmanchando a casa, vendendo a madeira. Aí me jogou para fora de casa. A casa era minha e eu não tinha onde morar".

Roselaine: "Eu falei que não estava gostando dos olhares dele para as pernas da minha sobrinha, aí ele bateu na minha cara. Ele foi viver com outra e agora moro de favor na minha irmã porque ele vendeu a casa que eu ganhei de herança".

Joana: "Agredia assim de palavras, umas palavras pesadas que fosse pior do que tivesse dado um tapa".

\section{(ii) Representações da violência}

Subcategorias: abusos físicos, humilhações e xingamentos, infidelidade

A diferença etária não impactou nas representações da violência, definida pelas entrevistadas como qualquer ato que cause sofrimento, dor e tristeza, ocorrendo por meio de agressões concretas ou subjetivas. A representação da 
violência apresentou semelhanças nas narrativas e a diferença geracional não foi significativa. Apesar de desconhecerem o Movimento Feminista, as representações dialogaram com as discussões contemporâneas sobre os direitos das mulheres. Isso ocorre porque o discurso feminista, seja para validá-lo ou lhe tecer críticas, está nos programas de TV, nas novelas, nas ruas, nas feiras e nos mercados, atingindo a todos/as.

A associação entre violência e violação de direitos humanos não ocorreu. A violência apareceu antes como "uma maldade", sem que os discursos adentrassem para o campo dos direitos de dignidade da pessoa humana. $\mathrm{Na}$ contramão do pensamento hegemônico na sociedade brasileira, a infidelidade conjugal foi considerada violência. É um dado significativo, pois contraria uma das mais sólidas normas patriarcais, que é a de uma feminilidade assexuada versus a pulsão sexual irrefreável dos homens ${ }^{11}$.

Rosa: "Violência não é só bater. Saía e arrumava outra mulher. Eu acho que isso daí já era uma violência".

Roselaine: "Uns falam que chifre dói menos do que apanhar de homem, mas eu acho que os dois doem por igual".

\section{(iii) Reação à violência}

Subcategorias: aceitação, rompimento

A cultura patriarcal brasileira legitima o controle e poder dos homens sobre as mulheres, levando-as, algumas vezes, à aceitação da violência, terminando por fazer com que elas se considerem merecedoras das agressões que incidem sobre seus corpos ${ }^{11}$. As entrevistadas relataram que trabalhavam para ajudar nas despesas da família; cuidavam dos filhos e da casa; mantinham-se fiéis, mesmo quando traídas, e "não mereciam as agressões dos parceiros". Dada as condições econômicas precárias, não tinham muita margem de negociação, mas buscavam o enfrentamento.

Roselaine: "A mulher tem de saber se defender para não viver apanhando de homem".

Nair: "Larguei dele e fui cuidar dos meus filhos".

\section{(iv) Dificuldades para romper o ciclo da violência}

Subcategorias: dependência econômica, dependência afetiva, redes de apoio deficitárias

O ciclo de violência em alguns relacionamentos é marcado pelo continuum de ameaças, agressões, momentos de reconciliação e harmonia, seguidos de novos conflitos ${ }^{12}$. Por que as mulheres não rompem essas relações abusivas? Para Porto e Bucher-Maluschke $e^{13}$, a busca de um salvador, os sonhos do amor romântico e a dependência financeira e emocional dificultam o rompimento desse ciclo instável. 
Rosa: "Eu pensava: Com 8 filhos para onde eu vou com? Gostava dele. Apanhava, apanhava, mas todo lugar que ele ia, eu estava do lado".

Nair: "Saí e arrumei uma casinha. Mas eu gostava muito dele. Foi meu primeiro namorado".

As mulheres não relataram apoio concreto, seja por parte dos familiares ou amigos, para abandonar relações abusivas. Normalmente, elas confessavam às mães, depois de um tempo e não sem constrangimento, que apanhavam dos parceiros. As mães tendiam a aconselhá-las à conformidade.

Rosa: "Minha mãe chegava e eu contava para ela. Ela falava: "Quando ele vier te bater, você corre".

Algumas buscavam apoio na religião.

Joana: "Pedi a Deus que me desse calma para aceitar".

Rosa: "A gente entrega tudo na mão de Deus".

\section{(v) Consequências da violência na saúde}

Subcategorias: adoecimento físico, adoecimento psicológico

Hodiernamente, a interpretação da doença em um viés biopsicossocial tem evidenciado o elo entre violência e comprometimento da saúde ${ }^{14}$. Mulheres vítimas de violência apresentam mais dores crônicas e procuram mais os postos de saúde. Um agravante é que as respostas médicas às mulheres vítimas de violência costumam se limitar às agressões físicas, desconsiderando, por despreparo, falta de interesse ou de tempo, os problemas mais subjetivos das mulheres, que exigiriam mais empatia dos profissionais de saúde ${ }^{15}$.

Aviolência causa graves problemas à saúde: síndrome do pânico, depressão, distúrbios alimentares, fibromialgias, distúrbios gastrointestinais, dores crônicas, cefaleias, invalidez, hematomas, distúrbios ginecológicos, aborto, doenças sexualmente transmissíveis, abuso de álcool e drogas, suicídios, entre outros. Vítimas de violência passam mais dias de cama; enfrentam mais cirurgias, consultas médicas, internações, idas a farmácias e consultas de saúde mental do que as mulheres que não são vítimas de violência ${ }^{16,14}$.

As entrevistadas consideram que as consequências da violência a que estiveram expostas repercutiam para além de tristezas e sentimentos de humilhação, mas se materializaram num adoecer concreto, evidenciado no corpo físico. Por isso, quando uma entrevistada diz que sente dores generalizadas e pressão alta devido à violência conjugal, interessa menos buscar outros entendimentos, tais como o de que ela está acima do peso, leva uma vida sedentária ou que faz uso de álcool. Estas seriam explicações atinentes a um discurso médico-científico que deixa escapar a significação mais ampla da saúde e do adoecer ${ }^{17}$. 
Roselaine: "Essas dores todas são desse sofrimento da vida".

Rosa: "Eu tinha de correr para o mato e esconder dele, debaixo de chuva, de dieta, aí agora tenho essa bronquite".

Nair: "Essa depressão que eu tenho hoje eu acho que é por causa das coisas que eu passei com aquele homem violento. Comecei a ter esquecimento. Fiz tomografia para ver se tinha tumor. Aí no eletroencefalograma dava que um lado da minha cabeça estava tudo branco".

Joana: "Toda semana eu vou ao postinho. Os médicos acham que a minha diabete é nervosa".

Quadro 1 - Nome da entrevistada e queixas de saúde autorrelatadas e relacionadas com a violência.

\begin{tabular}{l|l}
\hline Nome & Queixas de saúde autorrelatadas \\
\hline Roselaine & Depressão, aperto no peito e pressão alta \\
Nair & Depressão, perda de memória e medo de ambiente público \\
Rosa & $\begin{array}{l}\text { Bronquite, colesterol, problema de coração e dores generalizadas pelo corpo } \\
\text { Joana }\end{array}$ \\
\end{tabular}

Permitir que as mulheres falem de si ajuda a entendê-las numa perspectiva integralizada, gerando a necessária empatia para o cuidado com as vítimas por meio da implementação de políticas públicas promotoras de justiça e de saúde.

Os resultados não permitem falar em práticas de enfrentamento da violência, mas também não inferem que todas mulheres se comportassem com total passividade frente aos abusos sofridos, validando a terminologia "mulheres em situação de violência" ao invés de "mulheres vítimas de violência"18,19. Em consonância com a teoria da ação comunicativa de Habermas $^{20}$, que pensa a linguagem como uma ferramenta de transformação, a expressão "mulheres em situação de violência" sugere que elas podem resistir à violência e ressignificar suas histórias, validando o empoderamento feminino ${ }^{21}$. É importante reforçar que as mulheres não precisam ser eternas vítimas, ainda que nem todas consigam romper o ciclo de opressão. Além disso, a prática do diálogo exigirá homens capazes de rever suas masculinidades. Para Habermans, a comunicação é uma interação que se dá exclusivamente pelo entendimento linguístico como mecanismo coordenador da ação entre, pelo menos, dois sujeitos agentes ${ }^{20}$. Habermas conclui que, na ação comunicativa, os atores buscam estabelecer uma relação mediada pela linguagem, diferentemente da ação estratégica, em que cada um busca defender seu próprio interesse, desconsiderando e objetificando o outro. Por isso, a ação estratégica comporta sempre a coerção e a violência, enquanto a ação comunicativa busca o entendimento ${ }^{20}$.

As falas evidenciaram uma compreensão da violência de gênero retirando-a do âmbito exclusivo da corporalidade 
e inserindo-a no terreno das agressões subjetivas. A relação entre abusos físicos/psicológicos e adoecimento se fez presente nas narrativas, demonstrando que as mulheres estão conscientes dos agravos da violência. Embora o estudo seja restrito a um pequeno universo de mulheres integrantes de uma posição sociocultural específica, acredita-se que ouvir as narrativas das vítimas no estudo da temática da violência valida as experiências subjetivas das mulheres.

Defende-se que o debate sobre a relação entre violência praticada por parceiros íntimos e adoecimento pode ajudar os profissionais da saúde a traçarem diagnósticos mais precisos, evitando exames desnecessários e medicações que pouco contribuirão para a saúde das pacientes se não houver mudança nas condições concretas de vida das mulheres.

Conclui-se que a incorporação da problemática de gênero no entendimento da violência, vinculando a compreensão do binômio saúde/doença à perspectiva dos estudos feministas, deve se associar à luta por proteção aos direitos das mulheres. Isso implica a elaboração de políticas de empoderamento e a construção de novos modelos de masculinidade hegemônica; ambas medidas potencialmente importantes para promover saúde e assegurar qualidade de vida, mitigando a ocorrência de violência de gênero e suas repercussões.

\section{REFERÊNCIAS}

1. World Health Organization. Global plan of action to strengthen the role of the health system within a national multisectoral response to address interpersonal violence, in particular against women and girls, and against children. Switzerland; 2016. [Acessado em: 2020 mar 07]. Disponível em: https://apps.who.int/iris/bitstream/handle/10665/252276/ 9789241511537-eng.pdf;jsessionid=07398FDE3D21382F3B31F5B7DB40F0A6?sequence=1.

2. Minayo MCS, Souza ER, Silva, MMA. Institucionalização do tema da violência no SUS: avanços e desafios. Ciênc. Saúde coletiva. [Internet]. junho, 2018; [Acessado 2020 mar 07]. 2(6):2007-16. Disponível em: https://www. arca.fiocruz.br/bitstream/icict/27543/2/Institucionaliza\%C3\%A7\%C3\%A3oViol\%C3\%AAnciaSUS.pdf.

3. Marin YAO. Problematizando el discurso biológico sobre el cuerpo y género, y su influencia em las praticas de enseñanza de la biologia. Revista Estudos Feministas. [Internet]. Florianópolis, 2019; [Acessado 2020 mar 07] 27(3): e56283. Disponível em: https://periodicos.ufsc.br/index.php/ref/article/view/1806-9584-2019v27n356283/42057

4. Liebschutz JM, Rothman EF. Intimate-partner violence: what physicians can do? New Engl J Med. [In- 
ternet]. Nov., 2012; [Cited 2020 mar 07]. 367:2071-73 Disponível em: https://pdfs.semanticscholar.org/fbc2/9e3422ddb1b263178b1c45e4530bc306f571.pdf

5. Atlas da Violência. Instituto de Pesquisa Econômica Aplicada. Fórum Brasileiro de Segurança Pública. Brasília: Rio de Janeiro: São Paulo; 2019. [Acessado 2020 mar 07]. Disponível em: http://www.ipea.gov.br/portal/images/ stories/PDFs/relatorio_institucional/190605_atlas_da_violencia_2019.pdf

6. Mota A, Schraiber LB. Medicina sob as lentes da História: reflexões teórico-metodológicas. Ciênc. Saúde coletiva. [Internet]. Rio de Janeiro, Abril. 2014; [Acessado 2020 mar 07]. 19(4):1085-94. Disponível em: http://www.scielo. br/pdf/csc/v19n4/1413-8123-csc-19-04-01085.pdf

7. Portelli A. História oral como arte da escuta. Tradução: Ricardo Santiago. São Paulo: Letra e Voz; 2016.

8. Bardin L. Análise de conteúdo. São Paulo: Edições 70; 2016.

9. Moscovici S. Representações sociais: investigações em psicologia social. São Paulo: Vozes; 2003.

10. Santos AMR, Nolêto RDS, Rodrigues RAP, Andrade EMLR, Bonfim EG, Rodrigues TS. Violência econômico-financeira e patrimonial contra o idoso: estudo documental. Rev. esc. enferm. USP [Internet]. 2019; [Acessado 2020 mar 07].53:e03417. Disponível em: http://www.scielo.br/scielo.php?script=sci_arttext\&pid=S0080=62342019000100401-\&lngpt.

11. Chanter T. Disciplinar, controlar e normalizar a sexualidade feminina com Foucault e as amigas feministas: corpos dóceis e resistentes. In: Gênero: conceitos chave em filosofia. Porto Alegre: Artmed; 2011, p. 65-77.

12. Lucena KDT, Deininger LSC, Coelho HFC, Monteiro ACC, Vianna RPT, Nascimento JA. Análise do ciclo da violência doméstica contra a mulher. J. Hum. Growth Dev. [Internet]. 2016; [Acessado 2020 mar 07]. 26(2):139-46. Disponível em: http://pepsic.bvsalud.org/scielo.php?script=sci_arttext\&pid=S0104-12822016000200003\&lng=pt\&nrm=iso.

13. Porto M, Bucher-Maluschke JSNF. A permanência de mulheres em situações de violência: considerações de psicólogas. Psic. Teor. E Pesq. [Internet]. Set., 2014; [Acessado 2020 mar 07]. 30(3):267-76. Disponível em: 
http://books.scielo.org/id/7yzrw/pdf/njaine-9788575415887-09.pdf

14. Gregori R; Silva RV; Ribeiro HM. Desafios para o acesso e sistematização dos dados de violência contra as mulheres no Brasil: a experiência de implementação do observatório da mulher contra a violência. Boletim Legislativo. Senado Federal. Núcleo de Estudos e Pesquisas da Consultoria Legislativa. Brasil. Abril, 2018; 70. [Internet]. Disponível em: https://www12.senado.leg.br/institucional/procuradoria/pesquisa/desafios-para-o-acesso-e-sistematizacao-dos-dados-de-violencia-contra-as-mulheres-no-brasil-a-experiencia-de-implantacao-do-observatorio-da-mulher-contra-a-violencia-1

15. Arduim AS, Castilhos ED, Seerig LM, Bighetti TI. Perfil epidemiológico de lesões de violência física em mulheres: estudo transversal. Saúde (Santa. Maria). [Internet]. 2018; [Acessado 2020 mar 07]. 44(1):1-9. Disponível em: https://periodicos.ufsm.br/revistasaude/article/view/28467/pdf.

16. Batista KBC, Schraiber LB, D'Oliveira AFPL. Gestores de saúde e o enfrentamento da violência de gênero contra as mulheres: as políticas públicas e sua implementação em São Paulo, Brasil. Cad. Saúde Pública. [Internet]. 2018; [Acessado 2020 mar 07]. 34(8):e00140017. Disponível em: http://www.scielo.br/pdf/csp/v34n8/1678-4464-csp-3408-e00140017.pdf.

17. Czeresnia D. O conceito de saúde e a diferença entre prevenção e promoção. In: Czeresnia D, Freitas CM. (org.). In: Promoção da saúde: conceitos, reflexões, tendências. Rio de Janeiro: Fiocruz; 2003. p. 39-53. [Internet]. Disponível em: http://www.fo.usp.br/wp-content/uploads/AOconceito.pdf

18. Silva EB, Padoin SMM, Vianna LAC. Violência contra a mulher e a prática assistencial na percepção dos profissionais da saúde. Texto Contexto Enferm. [Internet]. Jan./Mar., 2015; [Acessado 2020 mar 07]. 24(1):229-37. Disponível em: http://www.scielo.br/pdf/tce/v24n1/pt_0104-0707-tce-24-01-00229.pdf.

19. Garcia, LP, Duarte, EC, Freitas, LRS, Silva, GDM. 2016. Violência doméstica e familiar contra a mulher: estudo de casos e controles com vítimas atendidas em serviços de urgência e emergência. Cad. Saúde Pública, [Internet]. Abr. 2016; [Acessado 2020 mar 07]. 32(4):e00011415. Disponível em: https://doi.org/10.1590/0102-311X00011415.

20. Habermas J. Teoria do agir comunicativo. Racionalidade da ação e racionalização social. Rio de Janeiro: 
Martins Fontes; 2011.

21. Marinho PAS, Goncalves HS. Práticas de empoderamento feminino na América Latina. Rev. estud. soc. [Internet]. Jun. 2016; [Acessado 2020 mar 07]. 56:80-90. Disponível em: https://journals.openedition.org/revestudsoc/9863. 